\title{
Overview of Path-Goal Leadership Theory
}

\author{
Alanazi, Talal Ratyan ${ }^{a^{*}}$, Alharthey, Bandar Khalafa, Amran Raslia \\ ${ }^{a}$ Faculty of Management, University Teknologi Malaysia, 81310 UTM Johor Bahru, Johor, Malaysia \\ *Corresponding author: talal_r9@hotmail.com
}

Article history

Received :4 April 2013

Received in revised form :

25 July 2013

Accepted :15 October 2013

\begin{abstract}
The role of leadership is very important, and it can affect the ecology of their organizations, business and employees. Effective Leadership can affect the subordinate satisfaction, motivation and performance. This study focuses on Path-Goal theory which is categorized under contingency approach. The theory proposed that the behavior of leaderships can be exercised in different situations and times by the same leader. Many studies have been conducted to test and verify the theory. In spite of the appealing nature of the path-goal theory, the empirical tests were difficult. The different ways for constructing the theory explain clearly some of the contradictions in theory testing. However, the fundamental empirical researches conducted to test the path-goal theory have proposed a necessity for further refinement for the path-goal theory.
\end{abstract}

Keywords: Path-goal theory; leadership; directive; supportive; participative; achievement oriented

(C) 2013 Penerbit UTM Press. All rights reserved.

\subsection{INTRODUCTION}

Recently, changes have become inevitable in all sectors, Organizations must be flexible to acquire all that is new in the surrounding environment, and try to cope with all the changes that occur around them to enhance their capabilities to compete effectively in the market in which they operate, or at least stay in the competition area. The leaders should be able to face the challenges accompanying the developing process of their organizations ${ }^{1}$.

In this process, the role of leadership is very important, and it can affect the ecology of their organizations, business and employees. Effective Leadership must be able to motivate their subordinates to do their best and exploit all their potentials to contribute to the development of the organization, as well as to achieve job satisfaction that contributes significantly to reduce the turnover rate among the employees. Different leadership and management strategies should be employed to achieve and ensure job satisfaction based on different situations ${ }^{2}$. Employee's motivation and achieving job satisfaction are very necessary to enhance the organizations' competitiveness ${ }^{3}$. The contribution of the subordinates is possible with the existence of effective leadership who directs and guides the subordinates to the right way to achieve the organizational goals.

\subsection{THEORETICAL UNDERPINNINGS OF LEADERSHIP}

There are many approaches on leadership field such as trait and personalities $^{4}$, behavioral ${ }^{5}$, contingency or situational ${ }^{6-9}$, transactional $^{10-11}$, transformational $^{12-14}$ and self leadership approach $^{15}$.

Path-Goal theory is categorized under contingency approach which concentrates on its studies on the interaction between the variables involved in a leadership situation and patterns of leadership behavior. On the other hand, these studies present another common approach for studying the leadership. The belief that denies the existence of a single leadership pattern for all cases becomes the base of the contingency or situational theories. The main leadership contingency models contain the leadership effectiveness model of ${ }^{16}$, decision making model of ${ }^{17}$, path-goal theory of ${ }^{18}$, and situational leadership theory of Hersey and Blanchard.

The path-goal theory of 18 is a different leadership contingency model which is based on the belief that an individual's motivation depends on the expectations that spending more effort to achieve better performance could be successful. This performance will be effective to avoid negative outcomes and to obtain positive rewards. House and Mitchell ${ }^{18}$ propose that the leadership behavior types which include directive, supportive, participative and achievement-oriented leaderships can be exercised in different situations and times by the same person. By applying one of these leadership behaviors, the managers try to affect the concepts of their subordinates, and pave the way for achieving their goals.

\subsection{PATH-GOAL THEORY DEVELOPMENT}

The Path-Goal theory developed by Robert House is the most effective contingency approach to leadership ${ }^{19}$. This theory 
indicates that the leader main objective is to provide guidance, support, and help necessary for subordinates to achieve their own goals effectively besides the organization goals ${ }^{20}$.

The theory includes two situational contingencies; the first one is group member's personal characteristics, and the second is the environment of work ${ }^{21}$. Four different types of leadership styles are suggested by this theory namely, participative, supportive, directive, and achievement-oriented leadership styles. A good leader should know which style to practice and when ${ }^{22}$. Directive leader explains to the subordinates what is expected from them, provide guidance, and ensure procedures and rules implementation. The supportive leader pays high attention to the subordinates' needs and wellbeing. On the contrary the participative leader encourages the subordinate's participation in the process of decision making whereas achievement-oriented leader attempts to enhance the performance, defines the standards, and ensures achievement of these standards by the subordinates ${ }^{23}$.

The task nature and the subordinate's needs will inform on the leadership style that the leader should choose. The degree of the task definition is inversely proportional to the level of guidance and direction need. The path-goal theory debates that a leader should be task or relationship oriented according to the requirements of the particular situation ${ }^{24}$.

The theory is based on two variant hypotheses. The first one is that when the subordinates consider the behavior of leaders as a source of satisfaction of their current job, which can be acceptable and achieve employee job satisfaction. The leader's behavior will be considered acceptable to his subordinates only when they feel that it is immediate source of their satisfaction or it can be useful to achieve job satisfaction in the future. The second hypothesis considers the behavior of leaders is a motive for the employees. So, if the behavior of leaders is convenient, it will lead for more motivation of the employees. Achieving subordinates' motivation can be done by linking their needs satisfaction to efficient performance. It can also be archived by completing the subordinates work environment through substantial coaching, direction, and rewards for their efficient performance ${ }^{25}$.

In the case of the existence of substantial pressure in the work environment or the vague structure of the work, more job satisfaction should be provided to the subordinates by the directive leadership on order to achieve effective performance. If the structure of the work is obvious, more job satisfaction should be provided by the supportive leadership to achieve effective performance. If the ability and experience of the employees are at high level, directive leadership may be not appropriate and may hinder the performance and job satisfaction of the employees. The leader should be more supportive than directive if the organization system is clear and rigid.

Based on the theory, the role of the leader depends on the work environment of the subordinates work and the structure size in this environment. Clear path to goals of the work can be achieved by highly structured environments with role and clarity of the task. In this case, the leader should be interested in his relationship with subordinates, supports the morale of the subordinate and decrease the task boredom as much as possible. If the structure of the work is unclear or changeable, the leader should support his subordinates by providing more direction and guidance. In this case, task orientation over relationship orientation should be chosen by the leader.

\subsection{THEORY TESTING}

\subsection{Supportive Literature on Theory Testing}

Path-goal theory investigations focus on exploring the relationships between the behaviors of the leadership and satisfaction while studying the impact of different moderator variables such as the characteristics of the task. For example, ${ }^{26}$ discovered the introductory support for the claim that situational variables may modify the directive leader behavior, in addition to the behavior of supportive leader, and effectiveness measures such as job satisfaction of the subordinates.

${ }^{27}$ stated that task variables characteristics such as assortment, feedback and social interaction modified the relationship between the behavior of directive leader and satisfaction. Also, according to ${ }^{28}$, in his meta-analysis of several studies, found support for the basic theory hypothesis, especially with respect to the behavior role of the directive leader, moderated by the task characteristics, on the satisfaction of the employees. Moreover ${ }^{29}$ discovered that the behavior of supportive leader strongly seems to be relevant to the satisfaction levels of the employees, irrespective of the situational characteristics. The findings of 30 and 31 in their meta-analyses support for an affirmative relationship between the behavior of supportive leader and the job satisfaction of the subordinates. Many studies ${ }^{32}$ support the hypothesis that the behavior of directive leader enhances the satisfaction of the subordinates not for structured tasks, but for unstructured tasks. The proposition that supportive behavior raises the role clarity for unstructured tasks only was weakly supported. The research stated that the impact of supportive behavior on subordinate satisfaction is only weakly moderated by the task structure.

House $^{26}$, found in one of the priori study stated that the subordinates' satisfaction was coupled with the degree of role ambiguity reduction by the directive leader behavior. Also, ${ }^{33}$ noticed that the behavior of directive leader was directly related to the satisfaction of subordinates with management by objectives. At the same time, when the scope of the subordinates' task is reduced, the leader became more concerned with the satisfaction and performance of the subordinates. ${ }^{34}$ conducted a test to the theory and found that when the behavior of the supportive leader remained constant, the behavior of directive leader is not linked to the satisfaction of the subordinates, and role clarity when the task ambiguity decreased. Silverthorne presented some support to the theory of the path goal. The main conclusion, of his study shows the success of this theory as a useful tool when applied to organizations in Taiwan, with the implication that the basic components of the path-goal theory leadership should be reflected by the managerial training and selection. Managers who have adapted to the theory basic principles might be better leaders and managers. Overall, results support the theory, particularly with regard to the relationship between leaders and subordinates.

${ }^{35}$ showed in his study that directive leadership is inversely proportional to leader subordinates acceptance and has negative contribution in job satisfaction with supervision and job in general when they have a high ability perception. Another study for ${ }^{36}$ showed that the highly supportive of leaders with a structured task situation made the people more satisfied. This result asserted the path-goal theory that when the subordinate task was structured or routine, a supportive leader motivates the subordinate by decreasing the work environment negative aspects.

Path-goal theory assumes that the subordinate outcomes will be affected by the behavior of participative leader positively 
in case of unstructured task. The results indicate that the high participative leadership has negative contribution in job satisfaction with supervision and job in general in case of structured task. ${ }^{37}$ point out that the relationship between all types of leadership behavior and employee job satisfaction is significant.

The Path-goal theory has three main strengths are identified. The first one, it introduces a theoretical frame work, which helps to understand the effect of directive, supportive, participative, achievement-oriented leadership styles on the subordinates productivity and satisfaction. The second strength, it is the first theory that introduces the concept of subordinates motivation of expectancy theory into its concept of leadership. The third strength, it introduces a practical model that confirms and illustrates the leaders important ways to help the subordinates ${ }^{38}$.

\subsection{Non Supportive Literature on Theory Testing}

In spite of the appealing nature of the path-goal theory, the empirical tests were difficult. For example, ${ }^{39}$ and ${ }^{40}$ proposed that some of the scales of Ohio State Leadership (which were frequently used to test the theory) were confounding measures. ${ }^{39}$ proved instrumentation affects the test of the path-goal theory. Therefore, the different ways for constructing the theory explain clearly some of the contradictions in theory testing. Bass ${ }^{11}$, Wofford \& Liska ${ }^{31}$, and ${ }^{41}$ have worked on this problem.

Other than theory testing, self-report measures are utilized to evaluate the leader behavior and dependent variables. 120 survey studies on path-goal theory were reviewed by Wofford and Liska, using the Meta analysis approach. They discovered scarce support for the proposition that the task characteristics will moderate the directive behavior effect on role clarity and the performance of the subordinates. Irrespective of the situation, a positive effect of supportive leadership on satisfaction has been informed by the literature.

However, many studies have to be conducted to test the proposition that satisfaction is increased through participation of leader in the case of unstructured task and the desire autonomy of the subordinates. ${ }^{42}$ conducted a survey in a hospital which involved many employees include administrators, professional, technical and the services. The results supported of the hypothesis of path-goal theory associated with task characteristics and the directive leader behavior and subordinate satisfaction relationship however, the result did not support the directive leader behavior and performance relationship.

Similarly, ${ }^{43}$ tested the hypotheses that relations between the behavior of directive leader and satisfaction were better in structuring low task, repetition low task and high task independence than under structuring high task, repetition high task and low task independence. The behavior of the supportive leader, the satisfaction of subordinates and role clarity were expected to be positively related. The respondents were project engineers, civil services personnel, and military officers. The results showed consistency with path-goal theory respecting the behavior of the supportive leader, and showed contrary to the theory with respect to the behavior of director leader.

44 figured out that satisfaction and performance outcomes depend directly on task characteristics and on the subordinates growth need. Path-goal prediction was tested by ${ }^{45}$ for library supervisors, reference librarians and cataloguers. Contrary to path-goal, the results showed that the performance of the direct leader was better when the structure of the task was high. The high educational level of librarians and their low independence need seemed to be possible explanations for the study results. Generally, the behavior of director leader raises tensions, particularly, when the behavior of supportive leader is low ${ }^{46}$. Moreover, ${ }^{47}$ stated that behavior of directive leader was positively related with the satisfaction and performance with little structured task. However, such behavior was negatively related to the work satisfaction if the tasks were better structured. As predicted from the theory, supportive leadership would increase the correlation with cardinal satisfaction if the task structure increased.

In another study, ${ }^{48}$ tested the causation that lies behind the theory. The findings supported the theory, expect, again, for the hypothesis related to the performance of the subordinates. ${ }^{49}$ found partial supports for the path-goal expectations, while Siegel ${ }^{34}$ and ${ }^{50}$ did not discover equivalent result. Dessler and Valenzi did not find that the moderator effects across supervisory levels. ${ }^{51}$ found that the results were stronger for the supportive hypothesis than for the directive hypothesis and stronger for satisfaction as criterion than for performance.

${ }^{52}$ conducted 48 path-goal studies with 11862 respondents. The findings showed that when work environment does not include the structure, the behavior of directive leadership enhances the subordinates' radical motivation and overall satisfaction. Contrary to the predictions, directive leadership enhanced the performance of the subordinates only when the measure of the structure was high. When the measure of the task structure was high, the behavior of supportive leadership enhanced the motivation, satisfaction, performance and role clarity as expected. 53 in his report deducted that the subordinates' overall satisfaction was affected by participative leadership. Moreover, the behavior of achievement-oriented leadership was relevant to raise radical satisfaction among subordinates in highly structured task, and to decrease radical satisfaction and performance among subordinates with highly achievement need.

Riffat et al. ${ }^{35}$ showed that subordinates motivation can be achieved when they work with directive leader and have high ability perception. This result contradicts the perception of path goal theory that the qualified subordinates always accept and more comfortable with the participative leaders. ${ }^{54}$ found that only participative leadership style has significant impact on job satisfaction. The result did not support the Path-Goal Theory which stated that participative leadership is not effective when the task is highly structured. The assumptions related to supportive leader behavior, leader acceptance and job satisfaction were not supported by the study of Riffat et al. ${ }^{36}$. It was deduced that subjects working under supportive leadership had inverse relationship with acceptance of leader and job satisfaction when the task was structured. This result contradicts the path-goal theory, which states that when the task structure is high, supportive leadership makes the work acceptable and people are more satisfied with supportive leader.

The Path-goal theory has four main weaknesses are determined. The first one is the difficulty to use the theory in a specific organizational setting because it comprises a large number of interconnected hypotheses sets. The second weakness is the lack of the research findings support to consistent and complete picture of the theory claims. The third one is the theory ambiguity in indicating the leader behaviors direct effect on subordinate motivation levels. The last one is the theory failure in perceiving the leadership transactional nature although it is leader oriented theory. Furthermore, the theory does not encourage the subordinates to participate in leadership process 38 . 


\subsection{CONCLUSION}

The Path-goal theory is the common theoretical evolution from contingency approach to the research of leadership, this originated from the framework on the prediction of motivation theory. ${ }^{55}$ and ${ }^{56-57}$ are the main contributors to the recent theory development. The essence of the theory is to explain that the behavior of the leader affect the subordinate' satisfaction, motivation and performance. The theory proposed that the behavior of leaderships can be exercised in different situations and times by the same leader. The fundamental empirical researches conducted to test the path-goal theory have proposed a necessity for the reformulation for the path-goal theories.

\section{References}

[1] J. Word, A. Bacon, R. Mackie. 2003. Inspiring Leadership: Staying afloat in turbulent times. Derby: Thomson Learning.

[2] R. House, T. Mitchell. 1974. Path-Goal Theory of Leadership. Contemporary Business. 9(4): 81-98.

[3] R. Yeo. 2006. Developing Tomorrow's Leaders: Why Their Worldviews Of Today Matter? Industrial and Commercial Training. 38(2): 63-69.

[4] R. Stodgill. 1953. Aspect of Leadership and Organization. Ohio: The Ohio Satate University.

[5] R. Stodgill, D. Coons. 1974. Handbook of Leadership: A Survey of Theory And Research. New York: Free Press.

[6] F. Fielder. 1967. A Theory of Leadership Effectiveness. New York: McGraw-Hill.

[7] V. Vroom, P. Yetton. 1973. Leadership and Decision Making. Pittsburgh: University of Pittsburgh Press.

[8] R. House, T. Mitchell. 1974. Path-Goal Theory of Leadership. Contemporary Business. 9(4): 81-98.

[9] P. Herset, K. Blanchard. 1977. Management of Organizational Behavior. Brentice Hall: New York.

[10] C. C. Mans, H.P. Sims. 1991. Super Leadership: Beyond the Myth of Heroic Leadership. Organizational Dynamics. 18-35.

[11] B. M. Bass. 1990. Bass and Stogdill's Handbook of Leadership. $3^{\text {rd }}$ ed. New York: Macmillan.

[12] J. M. Burns. 1978. Leadership. New York: Harper and Row.

[13] J. Dunham, K. A. Klafehn. 1990. Transformational Leadership and the Nurse Executive. Journal of Nursing Administration. 20: 28-34.

[14] K. W. Parry. 1996. Transformational Leadership: Developing an Enterprising Management Culture. Melbourne: Pitman Publishing.

[15] C. C. Mans, H. P. Sims. 1989. Super leadership: Leading Others To Lead Themselves. New York: Prentice Hall.

[16] F. Fielder. 1967. A Theory of Leadership Effectiveness. New York: McGraw-Hill.

[17] V. Vroom, P. Yetton. 1973. Leadership and Decision Making. Pittsburgh: University of Pittsburgh Press.

[18] R. House, T. Mitchell. 1974. Path-Goal Theory of Leadership. Contemporary Business. 9(4): 81-98.

[19] S. P. Robbins. 2005. Organizational Behavior. Upper Saddle River, New Jersey, Pearson, Prentice Hall.

[20] C. Silverthorne. 2001. A Test Of The Path-Goal Leadership Theory In Taiwan. Leadership \& Organization Development Journal. 22(4): 151158.

[21] R. L. Daft. 2005. The Leadership Experience. 3rd ed. Mason, OH: Thomson, South-Western.

[22] A. Rad, M. Yarmohammadian. 2006. A Study of Relationship Between Managers' Leadership Style And Employees' Job Satisfaction. Leadership in Health Services. 19(2): 11-28.

[23] S. B. Prasad. 1990. Advances in Comparative Management. Vol. 5. Jal Press, Greenwich, CT.

[24] D. Wren. 1994. The Evolution of the Management of Thought. $4^{\text {th }}$ ed. John Wiley, New York, NY.

[25] E. Levanoni, R. Knoop. 1985. Does Task Structure Moderate The Leaders' Behavior And Employees' Satisfaction. Psychological Reports. 57(2): 611-23.

[26] R. House. 1971. A Path-Goal Theory of Leader Effectiveness, Administrative Science Quarterly. 16(3): 19-31.

[27] C. Schriesheim, A. DeNisi. 1981. Task Dimensions As Moderators Of The Effects Of Instrumental Leadership: A Sample Applicated Test Of
Path-Goal Leadership Theory. Journal of Applied Psychology. 66(5): 189-192.

[28] J. Indvik. 1986. Path-Goal Theory of Leadership: A Meta Analysis. In Proceedings of the Academy of Management Best Papers Meetings. $189-192$.

[29] J. Schriesheim, C. Schriesheim. 1980. A Test Of The Path-Goal Theory Of Leadership And Some Suggested Directions For Future Research Personnel Psychology. 33(2): 349-370.

[30] B. Fisher, J. Edwards. 1988. Consideration and Initiating Structure and Their Relationships With Leader Effectiveness: A Meta-Analysis. Proceedings of the Academy of Management. 201-205.

[31] J. Woffard, L. Liska. 1993. Path-Goal Theories of Leadership: A MetaAnalysis. Journal of Management. 19(4): 857-76.

[32] B. M. Bass. 1985. Leadership And Performance Beyond Expectations. New York: Free Press.

[33] J. Siegel. 1973. Reconsidering "Consideration" In Leadership PathGoal Interpretation Of Satisfaction And Performance. Toronto: University of Toronto. Unpublished Manuscript.

[34] G. Dessler. 1973. An investigation of the Path-Goal Theory of Leadership. Doctoral Dissertation. Baruch College, The University of New York

[35] R. Awan. 2003. Relationship Among Leadership Behavior of College Principals and Their Subordinates' Job Satisfaction and Acceptance of Leader: Apath-Goal Approach. Doctor Thesis. University of the Punjab: Lahore.

[36] R. Awan, N. Zaidi, G. Noureen. 2011. Task Structure as Moderator of College Principals' Leadership Behavior and Their Subordinates' Outcomes. International Education Studies. 4(1): 134-143.

[37] S. Malik, H. Hassan, S. Aziz. 2011. Path Goal Theory: A Study of Employee Job Satisfaction In Telecom Sector. 2011 International Conference on Management and Service Science. IACSIT Press, Singapore. (8): 127-134.

[38] P. Northhouse. 2010. Leadership Theory and Practice. $5^{\text {th }}$ ed. Sage: United Kingdom.

[39] C. Schriesheim, S. Kerr. 1977. Theories And Measures Of Leadership: A Critical Appraisal. In J. Hunt and L. Larson (Eds.). Leadership: The Cutting Edge. Carbondale. IL: Southern Illinois Press.

[40] C. Schriesheim, R. House, S. Kerr. 1976. Leader Initiating Structure: A Reconciliation of Discrepant Research Results And Some Empirical Tests. Organizational Behavior and Human Performance. 15(2): 297321.

[41] C. A. Schriesheim, S. L. Castro, X.T. Zhou, L. A. Dechurch. 2006. An Investigation of Pathgoal And Transformational Leadership Theory Predictions At The Individual Level Of Analysis. Leadership Quarterly. 17: 21-38.

[42] A. Szilagyi, H. Simms. 1974. The Cross-Sample Stability of The Supervisory Behavior Description Questionnaire. Journal of Applied Psychology. 59(6): 767-770.

[43] J. Stinson, T. Johnson. 1975. The Path-Goal Theory Of Leadership: A Partial Test and Suggested Refinement. Academy of Management Journal. 18(2): 242-252.

[44] A. Seers, G. Graen. 1984. The Dual Attachment Concept: A Longitudinal Investigation of the Combination Of Task Characteristics And Leader-Member Exchange. Organizational Behaviour and Human Performance. 33(3): 283-306.

[45] C. Wolcott. 1984. The Relationship Between The Leader Behavior of Library Supervisors and The Performance of Their Professional Subordinates (Path-Goal Theory, Management). Dissertation Abstracts International. 45(5A): 1507

[46] R. Miles, M. Petty. 1977. Leader Effectiveness in Small Bureaucracies. Academy of Management Journal. 20(2): 238-250.

[47] C. Greene. 1979a. Questions of Causation in The Path-Goal Theory Of Leadership. Academy of Management Journal. 22(1): 22-41.

[48] C. Greene. 1979b. A Longitudinal Investigation of Modifications To A Situational Model Of Leadership Effectiveness. Proceedings, Academy of Management. Atlanta, GA. 52-58.

[49] H. Downey, J. Sheridan, J. Slocum. 1975. Analysis Of Relationships Among Leader Behavior, Subordinate Job Performance and Satisfaction: A Path-Goal Approach. Academy of Management Journal. 18(2): 53-262.

[50] G. Dessler, E. Valenzi. 1977. Initiation Of Structure And Subordinate Satisfaction: A Path Analysis Test Of Path-Goal Theory. Academy of Management Journal. 20(2): 51-259.

[51] T. R. Mitchell. 1979. Current Developments in the Field of Leadership. Presented at the International Meetings of The Institute of Management Science, Honolulu,Hawaii, June.

[52] J. Indvik. 1985. A Path-Goal Theory Investigation of SuperiorSubordinate Relationships. Doctoral Dissertation. University of Wisconsin: Madison 
[53] J. Indvik. 1986b. A Path-Goal Theory Investigation of AchievementOrientated and Participative Leader Message Behaviours. Paper, Academy of Management, Chicago.

[54] L. Yang. 2005. The Relationships between Managerial Leadership Styles and Subordinate Job satisfaction and Job Performance. Doctor Dissertation. University of South Australia.

[55] M. Evans. 1970. The Effects of Supervisory Behaviour upon the PathGoal Relationship. Organizational Behavior and Human Performance. 5(3): 277-298.
[56] R. House. 1999. Weber and the Neocharismatic Leadership Paradigm. Leadership Quarterly. 10(4): 563-74.

[57] R. Stodgill, D. Coons. 1974. Handbook of leadership: A Survey of Theory and Research. New York: Free Press. 